\title{
Unique Russian-to-English and English-to-Russian Translation Pedagogy Resource
}

\author{
Alexander Burak \\ Associate Professor of Russian Studies \\ Department of Languages \\ Literatures and Cultures \\ University of Florida \\ USA
}

Dmitry Yermolovich. Russian-English Translation: A Textbook for University Students. Second edition (amended). Moscow: "Auditoria Publishing," 2015. - 592 pp. ISBN 978-5-9905339-5-0.[Д.И. Ермолович. Русско-английский перевод. Учебник для студенто вузов. Издание второе, исправленное и дополненное. Москва. Auditoria. 2015]

Dmitry Yermolovich.An Instructor's Methodological Guide and Keys to Assignments: A Supplement to "Russian-English Translation: A Textbook for University Students." Second edition(amended). Moscow: “AuditoriaPublishing," 2015. - 192 pp. ISBN 978-5-9905339-7-4. [Д.И. Ермолович. Методические указания и ключи к учебнику “Русско-английский перевод. Учебник для студенто вузов." Изданиевторое, исправленноеидополненное. Москва. Auditoria. 2015]

Translating is an activity that can damage, distort, but, in some cases, also enhance and even improve upon the original text in terms of its cultural-esthetic impact on the reader. In the history of English-to-Russian translations of some classic English-language fiction there have been cases where the translations are arguably "better" than the originals. In other words, translation is a performative activity that can harm, hurt and enrage or engage, fascinate and enchant the reader.

Probably because of its invisible ubiquity, misconceptions about translation among the general public abound. Those who think they know a foreign language are automatically assumed to be able to translate into and out of it. The question of whether such language users were ever formally taught to translate seldom arises. The question of how to teach teachers of translation is also hardly ever raised, at least in the American Academe. If one has been translating for a long time, s/he is generally considered "a professional translator." However, a "professional" translator is not necessarily an "expert" translator, the latter, in some significant cases, having to be doubly cognitively and "eruditionally" equipped as compared with the creator of the original text. I substantiate this thesis in my book What it Takes to be a Translator: Theory and Practice (Saarbrücken/Germany: Lambert Academic Publishing, 2014). The popular psychology writer Malcolm Gladwell has come up with "the 10,000hour rule" which holds that it takes about 10,000 hours of "deliberate practice" in order to reach a world-class level in any field. Although the rule has never been scientifically tested and confirmed with reference to any particular language, I basically agree. Based on my own 50-year-long linguistic experience, I would argue that, starting from scratch, it is necessary to spend at least ten years (52 weeks x 10), engaging in "deliberate practice" of the four main language skills 4 hours a day 5 days a week, in order to achieve true advanced-level (in some cases, near-native) proficiency in a language like English. With reference to language, I prefer to talk about "a 10year rule."

Professor Dmitry Ivanovich Yermolovich of the Moscow Linguistic University is expertly proficient in his combined profession of translator, interpreter, translation instructor, lexicographer, and cross-cultural commentator. In his two-book Translation Manual, he charts a step-by-step route from an advanced command of English to a competent operation as a Russian-to-English "written translator." The Manual is designed for a twosemester course of 126 40-minute classroom periods and about as much time of independent work outside the classroom. 
In Yermolovich's words in the preface to the course, "the chief aim of this course of written translation from Russian into English is to enable the trainees to acquire professional competences required to perform top-quality written translations from Russian (as a native language or mastered to a degree approaching a native proficiency level) into English (as a foreign language) of highly complex texts ranging from sociopolitical through cultural, general economics, scientific and technological texts to any other currently topical texts."

The translation competences require the following skills:

- Analyzing and interpreting predicative units of meaning as the key means of communication in the context of paragraphs, texts, and whole discourse;

- Confidently applying established translation techniques and transformations to achieve an equivalent reproduction of a Russian text in English,

- Confidently deploying the whole range of English expressive means to achieve the desired effect in the target text;

- Analyzing, evaluating, and editing English translations.

The core material of the course consists of two main parts dealing with the key lexical-grammatical and predicative-syntactic difficulties arising in translating socio-economic, financial, and cultural discourse typically offered by the various print and electronic media. The two parts include 9 large sections and 98 subsections. There are 4 appendices at the back of the Manual with transliteration and name conversion rules for Russian, Belarusian, and Ukrainian. Each subsection introduces a theoretical issue followed by a series of analytical and practical assignments. A summarizing illustrative table with additional real-life translation examples concludes each subsection. There are 30 such tables interspersed throughout the text of the Manual. The 203 assignments of the Manual are supplied with answers and comments in the Keys supplement to the Manual. These also include step-by-step methodological instructions on how to introduce theoretical material, organize classroom work on the assignments, and monitor the students' progress.

It is an established practice at Russian translator-training schools to teach translation/interpreting from one's native language into a foreign language separately from teaching translation from a foreign language into one's native language. Russian translation pedagogy also presupposes that the student/trainee signing up for a translation/interpreting course already has a native (ideally), near-native (preferably), or very advanced (a must) command of the foreign language s/he is aiming to become expert at translating into or from. The difference between the Russian approach and the approaches generally adopted elsewhere in the world is rationalized by the fact that reception of a foreign language text is usually less complete and nuanced than production of a text in a native language, which results in a greater number of initial (pre-final-editing) variants of translation in one's native language. The translation instructor needs to bring these variants into sharper focus to cast off the overly "creative" ones. Given the complete feedback on the translation exercises in the form of translation keys with explanations in the accompanying Keys supplement, designed both for instructors and students, the translation instructor working in an American setting can use the course to focus American students' attention more sharply on the complex clusters of lexical-grammatical meaning in the Russian stretches of language under discussion, at the same time inviting the students to give additional variants of translating those stretches of language into English. In other words, an experienced translation instructor can turn this reception-and-production dynamic to great advantage by using the Manual "in reverse," as it were, to teach English-to-Russian translation to a class of less linguistically proficient English speakers. Given the immensity and graduated complexity of the theoretical and practical material in the Manual, the instructor has a lot of leeway for using it selectively with reference to a specific translation class.

The structure, content, and the operative aims of the exercises in the Manual also allow an American student to use the Manual as a self-study resource. The student can use the 30 tables laying out the typical lexical-semantical and syntactic difficulties arising in translating from Russian into English by first studying the English translations provided in the tables and then analyzing the Russian originals that gave rise to them. The same strategy is easy to use in working from the keys to the translations supplied in the Keys supplement back to the translation exercises and texts for translation in the Manual itself.

The Manual is unique in the Russian-English translation pedagogy in that it brings together theory and practice in a way realistically leading to acquiring expert skills in translation. An important quality of the two-book volume is that its units proceed from the simpler to the more complex assignments, accompanied throughout by feedback in the form of suggested assignment solutions. 
The additional advantage for native speakers of English is that they can use the solutions given in the Keys supplement for additional post-translation editing from the perspective of their style and pragmatic impact. This would generate additional translations that would enhance the students' interpretive skills as advanced language speakers and translators. Being a graduated template that trains an instructor of translation to be a more proficient instructor of translation, the Manual is a translation instructor's self-training manual as well, and as such a unique Russian-to-English and English-to-Russian translation pedagogy resource. 